\title{
3-D Microprobe Metrology
}

Federal Manufacturing \& Technologies

\author{
K. W. Swallow
}

KCP-613-8519

Distributed October 2008

\section{Final Report}

Approved for public release; distribution is unlimited.

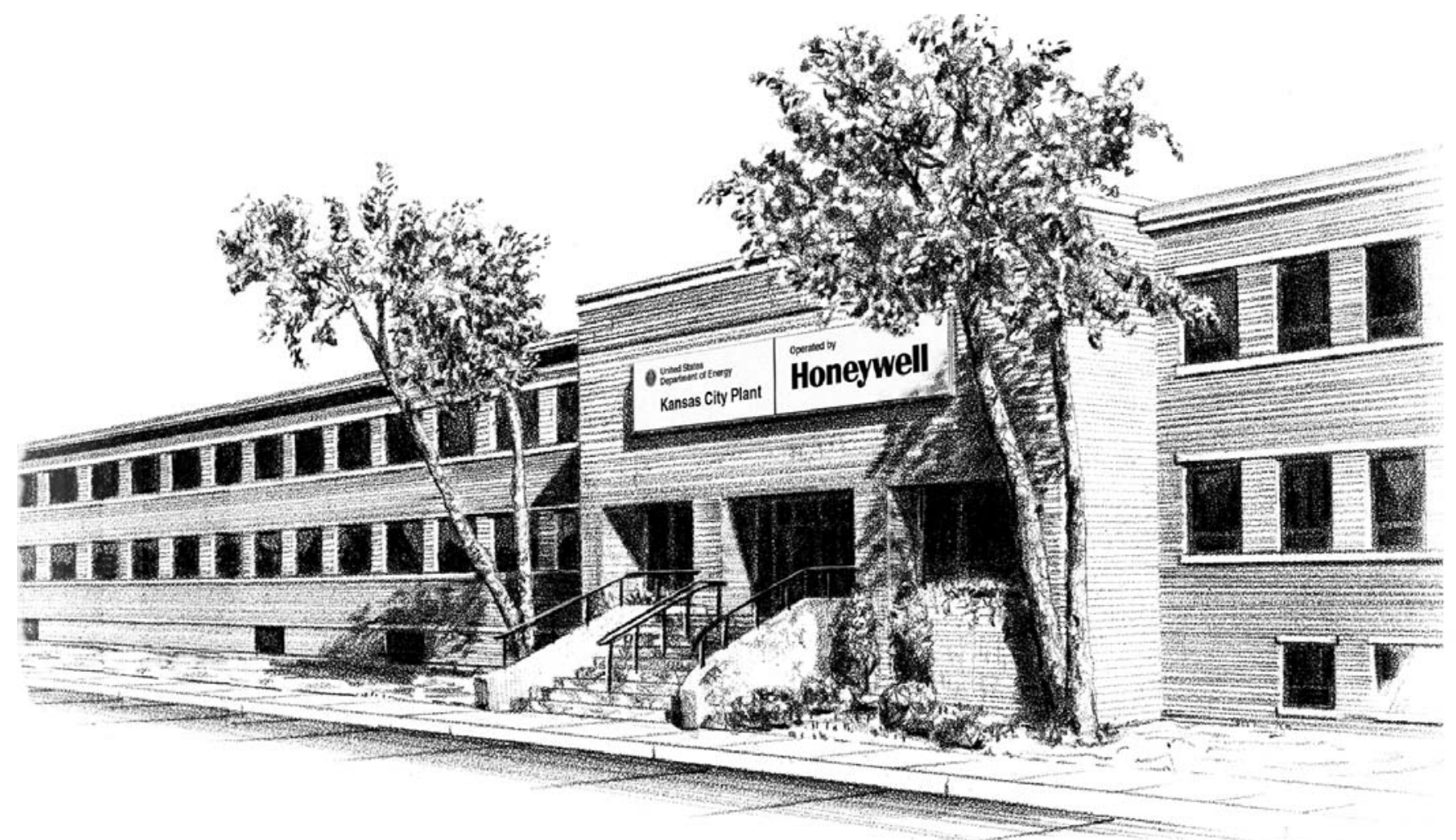

Prepared under prime contract DE-ACO4-01AL66850 for the United States Department of Energy 


\section{DISCLAIMER}

This report was prepared as an account of work sponsored by an agency of the United States Government. Neither the United States Government nor any agency thereof, nor any of their employees, makes any warranty, express or implied, or assumes any legal liability or responsibility for the accuracy, completeness, or usefulness of any information, apparatus, product, or process disclosed, or represents that its use would not infringe privately owned rights. Reference herein to any specific commercial product, process or service by trade names, trademark, manufacturer, or otherwise, does not necessarily constitute or imply its endorsement, recommendation or favoring by the United States Government or any agency thereof. The views and opinions of authors expressed herein do not necessarily state or reflect those of the United States Government or any agency thereof.

All data prepared, analyzed and presented has been developed in a specific context of work and was prepared for internal evaluation and use pursuant to that work authorized under the reference contract. Reference herein to any specific commercial product, process or service by trade name, trademark, manufacturer, or otherwise, does not necessarily constitute or imply its endorsement, recommendation or favoring by the United States Government, any agency thereof or Honeywell Federal Manufacturing \& Technologies, LLC.

Printed in the United States of America.

This report has been reproduced from the best available copy.

Available to DOE and DOE contractors from the Office of Scientific and Technical Information, P.O. Box 62, Oak Ridge, Tennessee 37831; prices available from (865) 576-8401, FTS 626-8401.

Available to the public from the National Technical Information Service, U.S. Department of Commerce, 5285 Port Royal, Rd., Springfield, Virginia 22161, (703) 487-4650.

A prime contractor with the United States Department of Energy under Contract Number DE-AC04-O1AL66850

\author{
Honeywell Federal Manufacturing \& Technologies \\ P.O. Box 419159 \\ Kansas City, Missouri, 64141-6159
}




\title{
Honeywell
}

\section{KCP-613-8519 \\ Distribution Category UC-47}

Approved for public release; distribution is unlimited.

\section{3-D MICROPROBE METROLOGY}

\author{
K. W. Swallow
}

Published October 2008

Final Report 



\section{Contents}

$\begin{array}{lll}\text { Section Page } & \text { Pag }\end{array}$

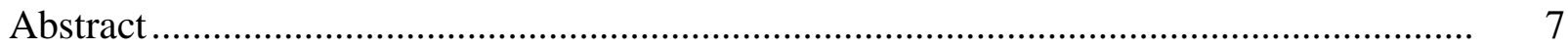

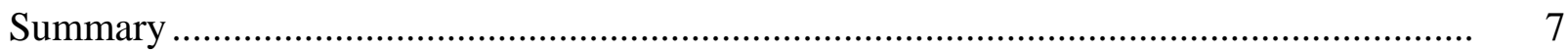

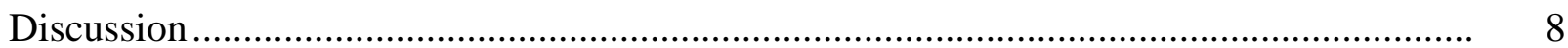

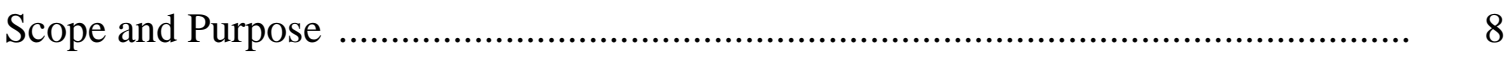

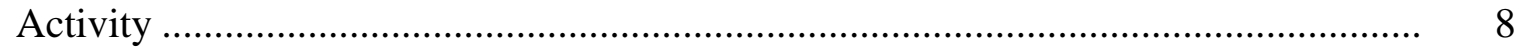

Review of Ultra-High-Accuracy CMM's Available in the Marketplace............ 8

Procurement of Ultra-High-Accuracy CMM............................................... 8

Development of Method for Calibration of Ultra-High-Accuracy CMM .......... 8

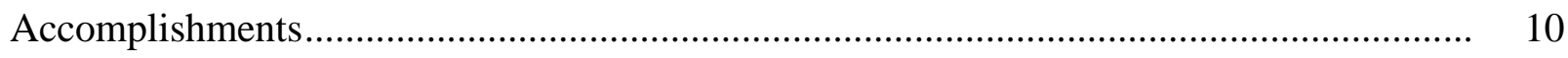

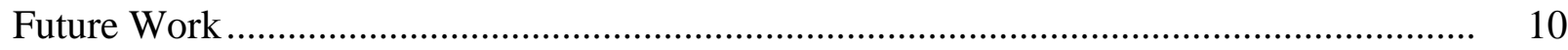

Appendices

A. Zeiss F25 Brochure ............................................................................. 11

B. Purchase Specification ....................................................................... 16

C. Evaluation of Ultra-High-Accuracy CMM................................................ 34 


\section{Illustrations}

$\begin{array}{lll}\text { Figure } & \text { Page }\end{array}$

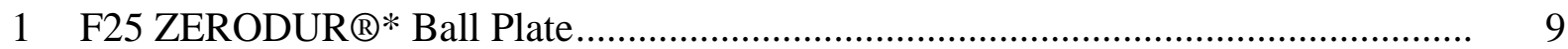

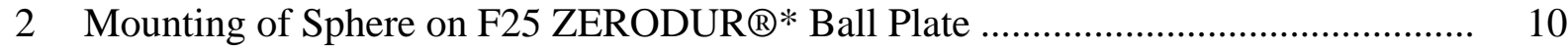

* ZERODUR is a trademark of Schott Glass Technologies, Inc. 


\begin{abstract}
This report documents the results of a project undertaken to develop an ultrahigh-accuracy measurement capability, which is necessary to address a rising trend toward miniaturized mechanical products exhibiting dramatically reduced product tolerances. A significant improvement in measurement capability is therefore required to insure that a 4:1 ratio can be maintained between product tolerances and measurement uncertainty.
\end{abstract}

\title{
Summary
}

An ultra-high-accuracy measurement capability is needed to address the rising trend toward miniaturized mechanical products exhibiting dramatically reduced product tolerances, and to address an increased customer focus on measurement uncertainty. A significant improvement in measurement capability is therefore required to insure that a 4:1 ratio can be maintained between product tolerances and measurement uncertainty.

During the initial phase of the project, currently available ultra-high-accuracy measurement capabilities were evaluated, and based on that evaluation, the new Zeiss F25 Microprobe Coordinate Measuring Machine (CMM) was selected for procurement.

In the next phase of the project, a purchase specification was written and funding was secured to proceed with procurement of the Zeiss F25 Microprobe CMM.

In the final phase of the project, calibration methods were evaluated, including the use of ultra high precision gage blocks and a ball-plate method developed by Zeiss. After evaluation of the various methods available for calibration of the machine, the ball-plate method was determined to be the optimum solution.

As a result of this project, an ultra-high-accuracy measurement capability has been realized, exhibiting a U95 measurement uncertainty of $\pm(0.25+\mathrm{L} / 666) \mu \mathrm{m}^{*}$ [English equivalent: $\pm(10+$ 1.66ppm) $\mu \mathrm{in}]$. Additionally, a method for calibration of the machine has been selected. (*: $\mathrm{L}$ is expressed in $\mathrm{mm}$.) 


\section{Discussion}

\section{Scope and Purpose}

The primary purpose of this project is to develop an ultra-high-accuracy measurement capability, which is necessary to address a rising trend toward miniaturized mechanical products exhibiting dramatically reduced product tolerances. A significant improvement in measurement capability is therefore required to insure that a 4:1 ratio can be maintained between product tolerances and measurement uncertainty.

The successful execution of this project is expected to yield an ultra-high-accuracy measurement capability, with a measurement uncertainty (U95) in the range of $0.25-0.50 \mu \mathrm{m}$ (English

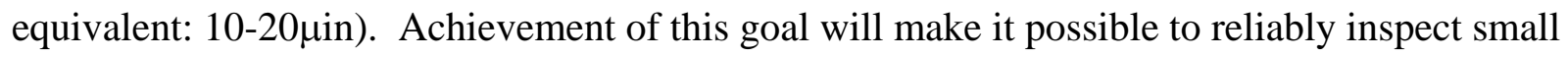
parts (maximum length of $75 \mathrm{~mm}$ ) with dimensional tolerances approaching $1.5 \mu \mathrm{m}(60 \mu \mathrm{in})$.

\section{Activity}

\section{Review of Ultra-High Accuracy CMM's Available in the Marketplace}

In search of a measurement technology with a U95 uncertainty somewhere in the $0.25-0.50 \mu \mathrm{m}$ range (English equivalent: 10-20 $\mathrm{in}$ ), it was determined that only one machine was available in the marketplace which could meet this performance criteria. The Zeiss F25 MicroProbe CMM is a new machine designed by Zeiss, with an U95 uncertainty statement of $\pm(0.25+\mathrm{L} / 666) \mu \mathrm{m} *$ [English equivalent: $\pm(10+1.66 \mathrm{ppm}) \mu \mathrm{in}]$. The capabilities of this machine include a 100x100x100 mm measurement volume, a touch probe system with a very low probing force, an optical axis for 2D optical inspection, a video system for viewing the probe and part throughout the measurement process, and a programming environment (Calypso) which can create inspection routines based on an imported solid model. A four-page technical brochure for this machine can be found in Appendix A of this report. (*: $\mathrm{L}$ is expressed in $\mathrm{mm}$.)

\section{Procurement of Ultra-High-Accuracy CMM}

After selection of the Zeiss F25 MicroProbe CMM, the next phase for the project was to write a purchase specification. A purchase specification was written; a copy can be found in Appendix $\mathrm{B}$ of this report.

\section{Evaluation of Ultra High-Accuracy CMM}

The Zeiss F25 performance was validated by a series of tests performed by Zeiss. The results of those tests can be found in Appendix $\mathrm{C}$ of this report.

\section{Development of Method for Calibration of Ultra-High-Accuracy CMM}

Calibration of the Zeiss F25 is a very challenging task due to the extraordinarily tight performance that the CMM is capable of providing. Two methods for calibration were 
investigated, including ultra high precision gage blocks and a ball-plate method developed by Zeiss.

Sandia National Labs developed a process for calibrating an early prototype model of the F25 CMM, and although this method provided generally acceptable results, it was discovered that this method exhibited several disadvantages:

- Collection of data with gage blocks was very time consuming.

- The gage blocks were subject to changes in length due to variation in the temperature environment.

- $\quad$ Outlier readings would sometimes occur due to foreign matter, which would then require re-collection of the data, or the outlier data point would have to be reviewed and possibly thrown out of the final dataset.

- The resulting data would not be compatible with the standard program used by the Kansas City Plant to analyze CMM performance and would therefore require a customized analysis program.

Based on Sandia's experience using gage blocks, it was clear that other methods of calibration should also be investigated.

Zeiss also recognized the disadvantages inherent to calibration using gage blocks and therefore developed a unique ball plate for calibration of the F25 CMM. Shown below in Figure 1 is a photograph of the F25 ZERODUR ${ }^{\circledR} *$ ball plate with an approximate size of $90 \mathrm{~mm}$ x $90 \mathrm{~mm}$.

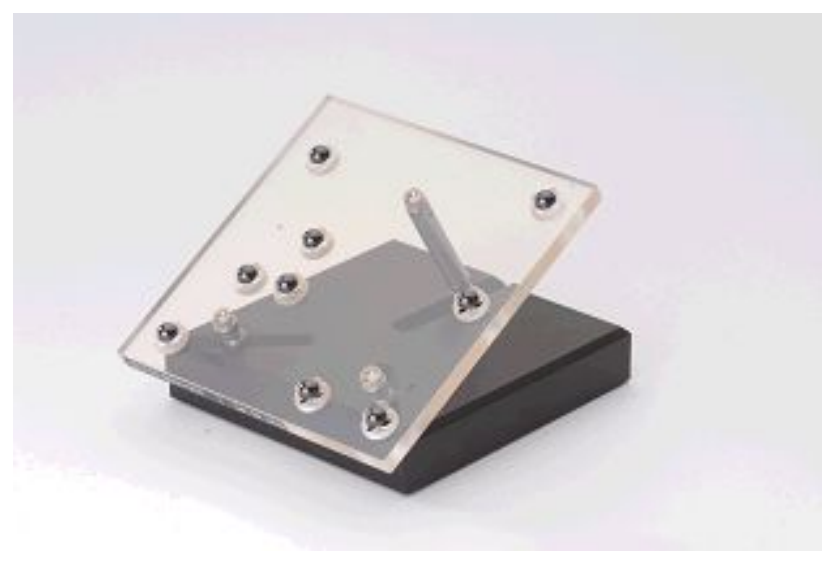

Figure 1. F25 ZERODUR® ball plate

* ZERODUR is a trademark of Schott Glass Technologies, Inc. 
The base plate of this artifact is made from ZERODUR ${ }^{\circledR *}$ glass, which exhibits an extremely low coefficient of thermal expansion. Nine spheres made from $\mathrm{Si}_{3} \mathrm{~N}_{4}$ are mounted onto the base plate. Nine kinematic mounting points are machined into the ZERODUR ${ }^{\circledR}$ glass, such that each sphere contacts the base plate at four discrete points, as shown in Figure 2 below.

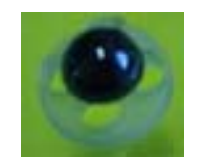

\section{Figure 2. Mounting of sphere on F25 ZERODUR ${ }^{\circledR}$ ball plate}

The uncertainty statement for the artifact is $\mathrm{U}_{\mathrm{xy}} \mu \mathrm{m}=\sqrt{(0.07)^{2}+\left(0.9 * 10^{-6} * \ell\right)^{2} \text {, where } \ell \text { is }}$
expressed in $\mu \mathrm{m}$.

Based on an evaluation of Sandia's experience using gage blocks, it was decided that the ballplate method would provide the most optimum solution for calibration of the CMM. Additionally, the ball-plate method would be more compatible with the standard software used by the Kansas City Plant to analyze CMM performance, and would therefore not require a customized analysis program.

\section{Accomplishments}

As a result of this project, the following has been achieved:

- The Zeiss F25 Microprobe CMM was identified as the best choice to achieve the required accuracy for inspection of small parts exhibiting tight tolerances.

- A purchase specification was written and a Zeiss F25 Microprobe CMM was purchased.

- The Zeiss F25 performance was validated by a series of tests.

- A method for calibration of the machine has been selected.

\section{Future Work}

Future work on this project will consist of the following:

- An F25 ZERODUR® ball plate will be purchased for calibration of the machine.

- A formal (written) calibration procedure will be created.

- Training for operation of the machine will be provided by Zeiss.

- Training for maintenance and calibration of the machine will be provided by Zeiss.

- An evaluation of the machine will be performed (using real piece parts) to characterize its strengths and weaknesses and to determine the "best practices" necessary to achieve the most optimum results.

* ZERODUR is a trademark of Schott Glass Technologies, Inc. 


\section{APPENDIX A}

Zeiss F25 Brochure 


\section{Fe5}

\section{Measuring Nanometers}

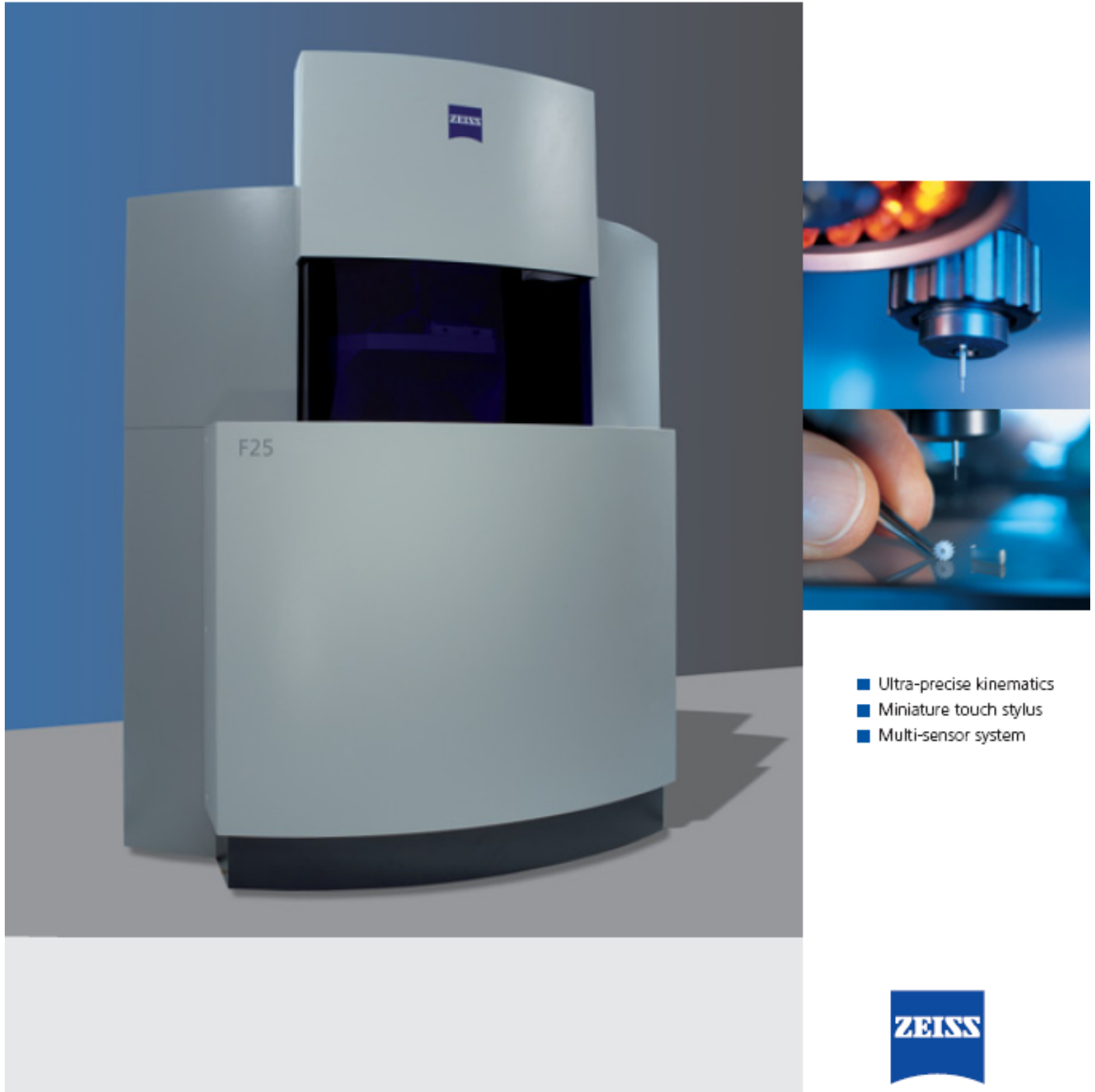

We make it visible. 


\section{Smallest Parts - Maximum Precision}

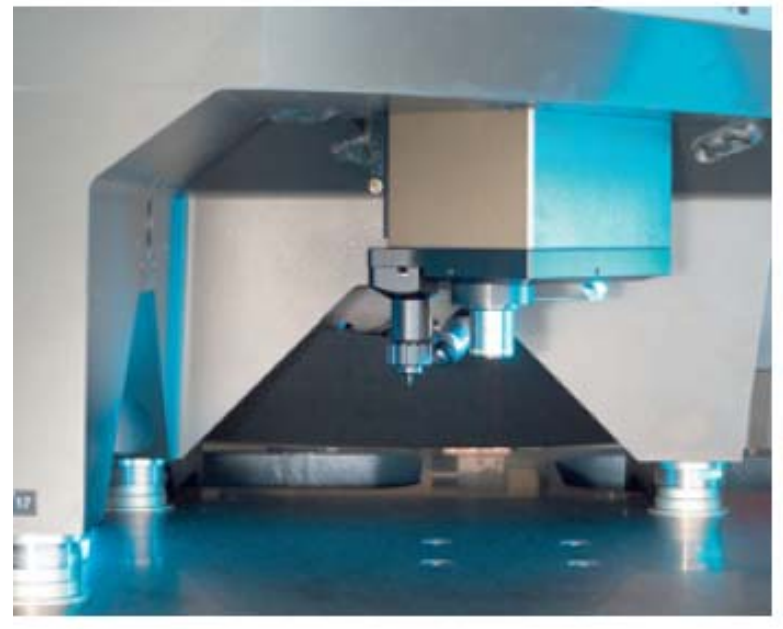

Qverview

3D coordinate measuring machines supported on air bearings with a measuring volume of one cubic decimeter. The ultra-precise kinematics combined with the highly accurate measuring system enable measuring uncertainty of 250 nanometers at a resolution of 7.5 nanometers. Using minimal probe forces, this resolution, along with optimum control of the linear drives, enables touch measurements even in bores less than one millimeter in diameter.
Micro-motors, micro-switches and precision components are showing up in more and more areas of our lives. Their reliability depends on their quality which is defined by measuring. With its intricate parts, micro-system technology is the challenge facing touch or optical measuring. Extremely small dimensions and different forces exist here; other principles apply. With the F25, Carl Zeiss has developed a coordinate measuring machine capable of measuring micro-system components.

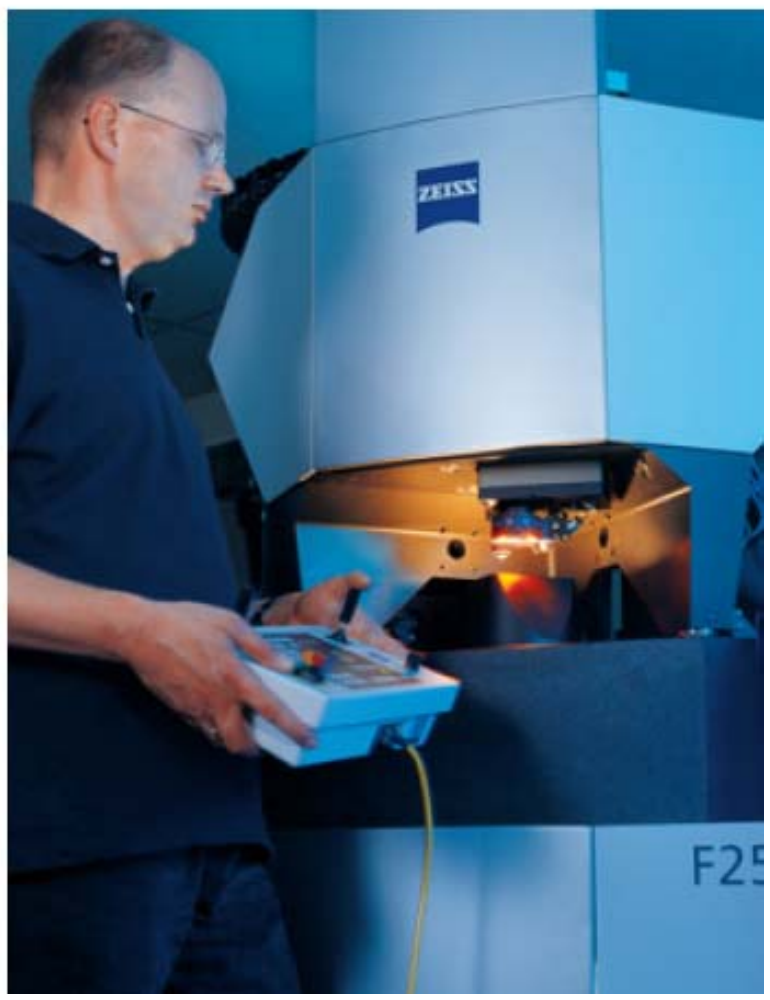




\section{Touch scanning sensor}

A touch, passive measuring stylus was developed based on a $6.5 \times 6.5 \mathrm{~mm}$ silicon chip membrane and integrated piezo-resistive elements. The stylus permits measurements in both single point and scanning mode.

The 3D micro-stylus is designed for stylus diameters of $50-500$ micrometers and stylus tip diameters of 100-700 micrometers. With a free shaft length of up to $4 \mathrm{~mm}$, it is possible to measure in small, deep-lying structures with probe forces of less than $0.5 \mathrm{mN} \mu \mathrm{m}$.

\section{Optical sensor}

The Viscan camera sensor from the standard program, combined with an objective lens based on those used in Zeiss microscopy, is used as an optical sensor for $2 \mathrm{D}$ measurements. These optics which are optimized for depth of field and have minimized distortion, ensure accurate measuring results with maximum resolution in reflected and transmitted light.

\section{Multi-sensor system}

The combination of touch and optical sensors enables measurements of $2 \mathrm{D}$ and $3 \mathrm{D}$ structures in the same coordinate system. An additional camera aids visualization when probing the miniaturized features, thus simplifying part programming.

\section{Software}

Time-tested CALYPSO from Carl Zeiss enables you to evaluate captured data using standard measuring software with an intelligent user interface that can also be used on all other coordinate measuring machines.

\section{Range of applications}

- Rotation symmetrical parts with freeform surfaces, small radii, undercuts

- Prismatic parts with small and deep bores

- Flat metal parts with low form stability

- 2D parts with bores and cut-outs

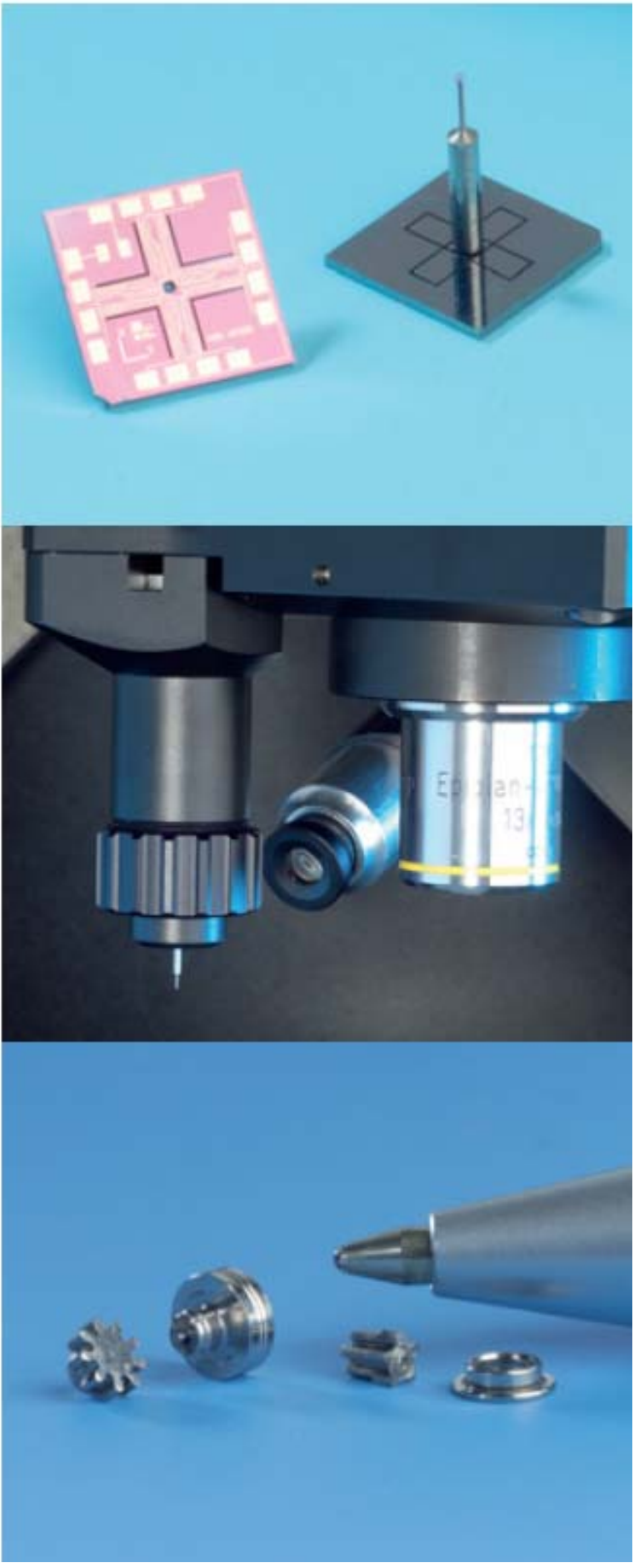




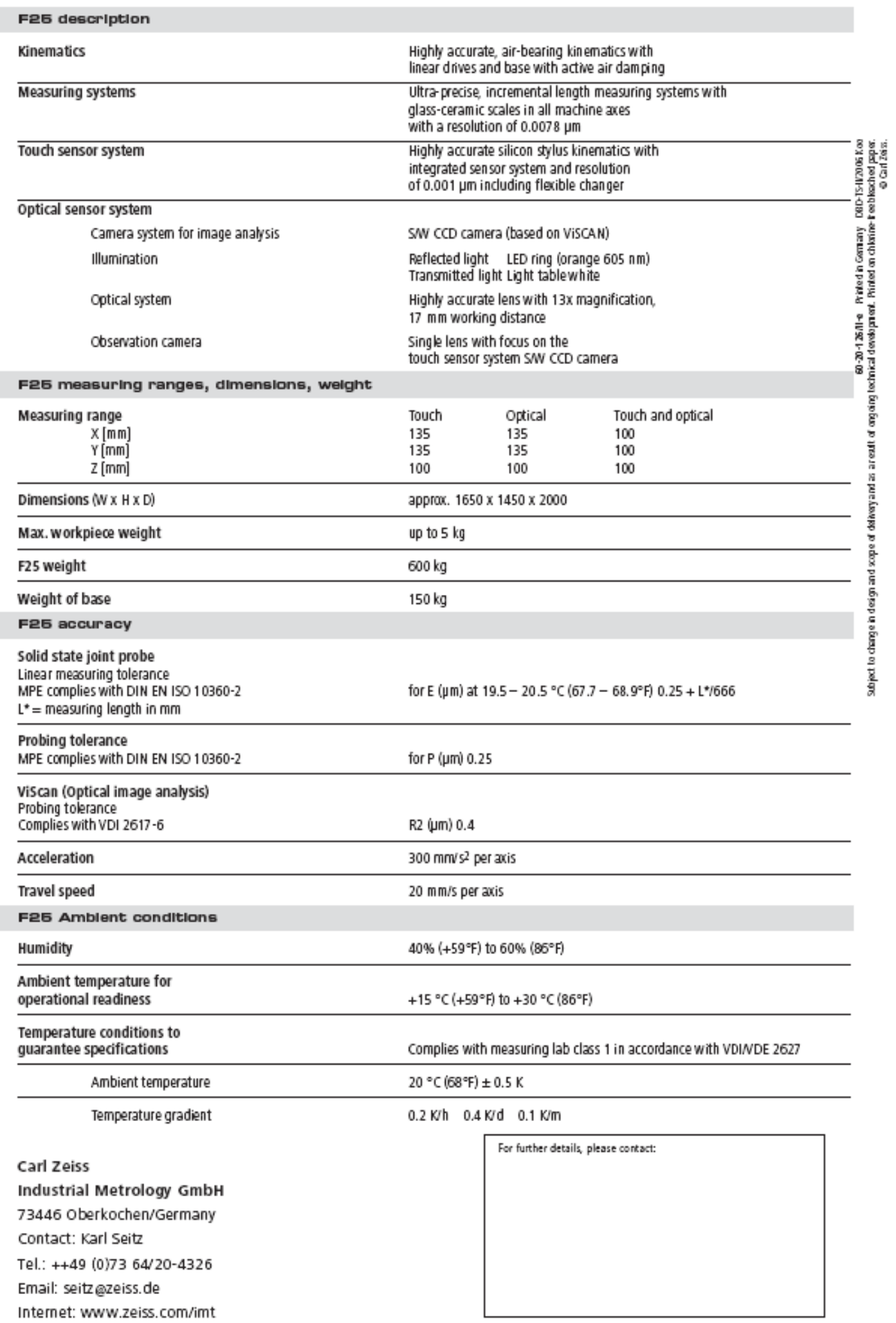




\section{APPENDIX B}

Purchase Specification 


\section{SPECIFICATION FOR \\ COMPUTER CONTROLLED HIGH-ACCURACY MICRO-PROBE COORDINATE MEASURING MACHINE}

\subsection{PURPOSE}

This specification defines the minimum requirements for a High-Accuracy multi-axis micro-probe Coordinate Measuring machine (CMM). The machine shall have a tactile probing system consisting of a scanning piezo micro-probe head, a measuring structure with three linear axes, a two-dimensional camera based optical measuring system and a camera based navigation system. All machine motions shall be provided with manual and Computer Numerical Control (CNC). The machine shall be capable of measuring the sizes and locations of a wide variety of features, and profile of parts in inch (in.) and millimeter $(\mathrm{mm})$ units. The machine with its numerical control and data analysis system, shall constitute a completely functional system with operations that are completely programmable by means of a digital storage medium such as magnetic disk. This specification defines the minimum requirements for the manufacture, performance and acceptance of a Coordinate Measuring Machine (CMM) that will be used for the dimensional inspection of tightly toleranced parts.

The purpose of this equipment is to automatically measure the features of parts for conformance to Engineering Requirements, Quality Acceptance and for process evaluation and control. The measuring system shall provide printed and electronic output of all features measured and a comparison of the actual measured results to the Engineering Drawing Requirements.

\subsection{GENERAL REQUIREMENTS, STANDARDS, AND CODES}

Paragraphs 2.1 through 2.11 define the minimum requirements for compliance with Environmental, Safety, and Health requirements.

2.1 The machine shall meet the following National Fire Protection Association (NFPA) Codes and Standards: NFPA-30, Flammable and Combustible Liquids Code; NFPA-70, National Electrical Code; and NFPA-79, Electrical Standard for Industrial Machinery and Appendices. If the specified U.S. standards cannot be met, equivalent European standards shall be required.

2.2 All Seller supplied coolants or lubricants shall have flash points of a Class III B liquid, at or above $200^{\circ}$ Fahrenheit (F), per National Fire Protection Association (NFPA) 30.

2.3 All components, where applicable and available, shall be Listed, Classified, or Recognized, and shall be labeled by a Nationally Recognized Testing Lab (NRTL), such as Underwriters Laboratory (UL) and/or Factory Mutual (FM), for their intended application.

2.4 All electrical and electronic components and wiring shall be safeguarded from accidental contact by the operator, and all switches and controls accessible to the operator shall not exceed 120 volts potential across the contacts or the equipment ground.

2.5 All energy service controls shall have a means to be locked and tagged to comply with 29 CFR 1910.147, The Control of Hazardous Energy (Lockout/Tagout).

2.6 All packaged assemblies and subassemblies of the system having internal voltages exceeding 50 volts shall be affixed with a label which states, "DANGER - ELECTRICAL SHOCK HAZARD", and/or shall be identified with a label with the internationally recognized symbol for high voltage. 
2.7 Inter-connecting electrical lines from the machine to the control shall be routed over the floor. Any tripping hazards shall be minimized with a protective floor track. The Seller shall provide all related protective hardware.

2.8 The equipment shall be supplied with a red mushroom-type Emergency Power Off (EPO) button at the operator station. Activation of the EPO shall return clamped components to the least hazardous condition, and shall cause a braked shutdown of rotational components. When activated, the EPO shall require a manual reset, and shall not cause any damage to the equipment. Where appropriate, other portions of the equipment shall have additional EPO buttons

2.9 The equipment shall comply with 29 CFR 1910, Subpart O, and shall be equipped with the following minimum guards and interlocks:

2.9.1 Guards, shields, or other protective covers shall be required to cover injurious high or low temperature parts and hazardous moving parts, e.g., pulleys, belts, drive shafts, drive screws, sharp edges, pinch points, or other potential hazards.

2.9.2 All guards and shields shall be constructed to provide access to the guarded parts for maintenance and shall not interfere with operation of the machine.

2.9.3 All guards and shields shall require the use of a tool for removal.

2.9.4 Switches and levers that actuate moving parts of the system shall be designed or guarded to prevent inadvertent activation.

2.9.5 Interlocks shall be required whenever access can be gained, without the use of a tool, to an area that would allow inadvertent contact with electrical or mechanical hazards. Examples of such include, as a minimum, remote or programmed system starts, moving and rotating mechanical parts, hazardous electrical potentials, hazardous energy levels, including microwave and radio frequency energy, laser beams, ionizing and other non-ionizing radiation, capacitor discharge, or operation of the system without shields and covers in place.

2.9.6 Interlocks shall be required whenever access can be gained, without the use of a tool, to an area where a rotational hazard exists. Actuation of the interlock shall cause an immediate and braked rotational shutdown with an alarm actuated. Additionally, no rotational activities shall begin with the interlock actuated.

2.10 The machine and associated equipment shall not emit noise levels in excess of 80 decibels ("A" scale) except as follows: The noise levels shall not exceed 75 decibels ("A" scale) in the areas attended by operators. Test acceptance shall be based on an 8-hour time weighted average (TWA) measured in accordance with procedures and conditions specified in Section 10 of the publication, "Noise Measurement Techniques", January 1976, or latest edition issued by the AMT (formerly the NMTBA). These measurements shall be performed only under the operating conditions (unloaded mode) specified in Section 10.1.3.b of the publication.

2.11 The machine shall be lead free, shall contain no asbestos or asbestos containing materials, and shall be free of PCB's.

Paragraphs 2.12 through 2.19 define the minimum requirements that must be met or provided for installation in the Buyer's facility.

2.12 The machine shall be arranged to operate from a 480 volts (V), three-phase, 60 hertz $(\mathrm{Hz})$ Delta power supply and shall contain step down transformers as an integral part of the electrical system for components requiring other than $480 \mathrm{~V}$ service. The equipment may be wired to operate from a 120/208 V, single-phase, $60 \mathrm{~Hz}$ power supply provided the service size does not exceed 30 
amps. The equipment shall not be affected by line voltage variations of $\pm 10 \%$ from nominal or transient voltages of 2500 volts maximum. The Seller shall be responsible for providing AC line conditioning devices for equipment not compatible with the voltage variation and transient parameters specified above. All transformers and capacitors supplied shall be of the "dry type" and shall not contain Polychlorinated Biphenyl's (PCBs).

2.13 All power and control circuits shall be provided with overload and under voltage protection.

2.14 Provide RK1 rates fuses in the 480 Volt supply circuit for the system if machine operates on 480 Volts.

2.15 If applicable, All AC electrical motors larger than 1/3 Horsepower (HP) shall have a power factor rating at full load and rated voltage of at least $85 \%$.

2.16 Leveling devices shall be furnished as an integral part of the machine base or shall be provided separately.

2.17 The machine and all ancillary equipment, including access doors, shall be designed and constructed to be installed in an area no larger than 12' wide, 12' long, and 10' high. This includes a minimum 3' clearance between the enclosure wall and the machine.

2.18 The machine shall be delivered in components that are sized to facilitate rigging from the Buyer's receiving dock to the installation site. Each component shall be no larger than 8'6" wide x 8'6" high.

2.19 The machine shall be designed and constructed for installation on the Buyer's floor without a special foundation. The Buyer's floor is constructed for uniformly distributed live load equipment installations up to 250 pounds per square foot.

Paragraphs 2.20 through 2.33 define the minimum requirements for facilitating routine maintenance and for conducting diagnostic testing of the equipment by the Buyer's maintenance personnel.

2.20 The machine control unit shall be of solid state, modular construction. Plug-in circuit boards shall be functionally coded for identification and to facilitate location in the control. All circuit diagrams and schematics shall be current, describe accurately the electrical systems actually furnished with the machine, shall be detailed to provide basis for analysis of defects in performance by the Buyer's maintenance personnel, and shall be written in English.

2.21 The machine control unit shall provide a means for diagnostic testing.

2.22 All wiring to components and controls shall be color-coded or labeled at each terminal point.

2.23 The machine and its parts, including seals, hoses, and paints, shall not be damaged or destroyed by normal fluids, such as cleaning products that would typically be used in a precision inspection environment.

2.24 All associated hydraulic, cooling, or lubricating system reservoirs or tanks shall be provided with secondary containment (e.g., primary tank contained within a secondary tank or catch troughs in the machine) sufficient to completely contain the contents of the reservoir or tank in the event of a leak or sudden release.

2.25 All bearings exposed to chips, water, or coolant shall be sealed.

2.26 If any periodic lubrication is required for maintenance purposes, automatic, forced feed lubrication shall be provided for all rotating parts requiring lubrication with metered, forced lubrication to sliding components. Each reservoir shall be equipped with a means for indicating oil level and shall be visible without requiring removal of any machine components. A low oil-level safety 
device shall give warning should the oil drop below a preset lower limit. Oil capacity shall provide for a minimum of 160 hours of lubrication. The fill points of all lubrication reservoirs shall be accessible from the floor, capable of being filled from outside the machine and identified with the recommended lubricant. The drain points of all lubrication reservoirs shall be identified and accessible from the floor. Automatic forced feed lubrication is not required for those rotating or sliding parts that are permanently lubricated (packed grease), lubricated from a reservoir, partially submerged in lubricant or do not require lubrication such as air bearings.

2.27 All instruction plates shall be in the English language.

2.28 All gages, scales, and dials shall be calibrated in both the metric and the United States (US) systems of measurement and/or the US system of measurement. All digital readouts shall be capable of both US and metric input and output, and shall be switchable on command.

2.29 The machine shall be provided with limit switches in all directions of travel to prevent over travel.

2.30 Electric servo drive units shall be provided for all axes.

2.31 Feedback devices, including resolvers, encoders, scales, and tachometers shall be limited to non-contact coupling and shall be isolated from extraneous line noise and fluctuations. Optical feedback devices shall not use incandescent filaments.

2.32 If a hydraulic system is required, it shall be constructed with the following features:

2.32.1 The hydraulic system shall include a tank, pumps, cooling system, valves, hydraulic motors, filters, connecting pipes and hoses, and all other components necessary for a functional system.

2.32.2 All metal plumbing in the hydraulic system shall be fabricated from rigid seamless steel tubing. For pressures exceeding 200 psi, SAE 1010 dead-soft, cold drawn seamless-steel tubing (or equivalent) shall be used. A safety factor of eight over maximum normal working pressure shall be used.

2.32.3 Where threaded connections are required, American National Standards Institute (ANSI) B2.1 shall be met. A safety factor of eight over maximum normal working pressure shall be used.

2.32.4 Tubing runs shall have as few bends as possible, but should have at least one bend to provide thermal expansion and contraction. The minimum radius of tube bend shall be three tube diameters.

2.32.5 Hoses used for flexible connections shall be steel reinforced, designed for the hydraulic fluid being used, and capable of withstanding four times the maximum normal operating pressure. Hose couplings, fittings, and minimum bending radius shall be in accordance with the hose manufacturer's instructions. Hoses shall not be permitted to rub against any other object as a result of machine movement, vibration, or pressure surges.

2.32.6 If hydraulic servo type drive units are utilized, the line filters shall be placed directly ahead of the servo units.

2.32.7 The hydraulic system shall be designed to use a Factory Mutual approved "less hazardous hydraulic fluid."

2.32.8 The pumps, seals, gaskets, packings, and other system components shall be suitable for use with less hazardous hydraulic fluid.

2.32.9 Emergency shutoff switches shall be provided for shutting down the hydraulic pumps in the event of a pipe failure or fire. The switches shall be accessible and well marked. 
2.32.10 A means shall be provided for controlling the hydraulic fluid temperature if normal operation of the equipment causes the fluid temperature to exceed $120^{\circ} \mathrm{F}$.

2.32.11 The hydraulic pump(s) shall automatically shut down upon loss of the cooling capability.

2.33 If refrigerants are required, the refrigerant shall be compatible with systems supported by the Buyer. A listing of all refrigerant types used shall be provided to the Buyer for approval.

2.34 If any liquid tanks are electrically heated, then two mean of providing dry firing of the heating tanks must be provided, such as a float switch and an interrupt circuit on the heating element.

\subsection{SPECIFIC DESIGN REQUIREMENTS}

3.1 General Machine Requirements

3.1.1 Machine guide ways shall be designed to retain alignment without being adjusted for a minimum of twelve (12) months. Way composition, design, and construction shall provide friction characteristics that will permit precise control of slide movements without sticking or overshooting of slides at any traverse rate or increment of slide movement.

3.1.2 Fixed, accordion, shade type, or telescoping type covers shall protect the slide ways, lead screws, and precision measuring devices from damage from dust, dirt, abrasives, and other foreign objects.

3.1.3 Air bearings shall be utilized for all bearing surfaces on the machine guide ways.

3.1.4 The machine shall employ linear drive technology on the $\mathrm{X}, \mathrm{Y}$ and $\mathrm{Z}$ axes.

3.1.5 Pre-lubricated sealed bearings shall be utilized for bearings of all rotating parts if rotating parts are utilized.

3.1.6 The machine shall be a kinematic, complex bridge/carrier type machine with stationary machine table and orthogonal bridge drive. The machine geometry will employ multiple axis carriers that minimize geometry errors such as Abbe offset errors.

3.1.7 The machine table shall be constructed of high quality granite with threaded inserts provided to mount parts or tooling and installed using center distances not to exceed 50mm (2 Inches) where practical in the measuring volume. An alternative holding fixture or vise shall be supplied if it is not practical to install threaded inserts into the granite.

3.1.8 The measuring volume shall employ an enclosure to isolate the measuring volume from dust and other environmental noise variables and shall employ a moveable or removable cover of transparent or translucent material.

3.1.9 The machine shall be so constructed that when installed and connected to power, it shall be ready for operation. The structure shall be capable of withstanding all forces encountered during operation of the machine to its maximum ratings and capacities without permanent distortion.

3.1.10 All castings and forgings shall be free of defects, scale and mismatching. Welding, peening, plugging, and filling with solder or metallic paste shall not be used for reclaiming any defective part for use in the machine.

3.1.11 All ceramic and composite components shall be free of defects and cracks, stable with humidity change. 
3.1.12 Welding, brazing, and/or soldering shall be employed only where specified in the original design. None of these operations shall be employed as a repair measure for any defective part.

3.1.13 All screws, pins, bolts, and nuts shall be installed in such a manner as to prevent change of tightness. Those subject to removal or adjustment shall not be swaged, peened, staked, or otherwise permanently deformed.

3.1.14 All surfaces of castings, forgings, molded parts, stampings, and welded parts shall be cleaned and free from sand, dirt, fins, sprues, flash, scale, and flux. All edges shall be either rounded or beveled unless sharpness is required to perform a necessary function. The condition and finish of all surfaces shall be commensurate with the Seller's standard commercial practice.

3.1.15 Diameter of dials shall be such that all graduations can be easily read. Dial type mode switches shall be marked with captions which show clearly and legibly the type functions to be performed. Dials shall be permanently imprinted, engraved, or etched and shall have a contrasting non-glare finish. All words shall be in English.

3.1.16 The overall machine dimensions, including the vibration isolation system shall not exceed the following limits:

Width (X axis) - $\quad 1700$ mm (67 Inches)

Length (Y axis) - 1700 mm (67 Inches)

Height (Z Axis) - 2500 mm (98 Inches)

\subsection{General Capacity and Performance Requirements}

3.2.1 The machine's three linear axes shall have minimum measuring ranges (travel movements) as follows:

$X$ axis - $\quad 100 \mathbf{~ m m ~ ( 3 . 9 ~ I n c h e s ) ~ O p t i c a l ~ a n d ~ T o u c h ~}$

$Y$ axis - $\quad 100 \mathbf{~ m m ~ ( 3 . 9 ~ I n c h e s ) ~ O p t i c a l ~ a n d ~ T o u c h ~}$

Z Axis - $\quad 100 \mathbf{~ m m ~ ( 3 . 9 ~ I n c h e s ) ~ O p t i c a l ~ a n d ~ T o u c h ~}$

3.2.2 The machine work surface shall have a minimum workload capacity of $5.0 \mathrm{Kg}$. (11 pounds.)

3.2.3 As applicable, the rotary table work surface shall have a minimum workload capacity of 0.50 Kg. (1.1 pounds).

3.2.4 The resolution of the $X, Y$, and $Z$ axis scales on the kinematic bridge structure shall be 0.008 $\mu \mathrm{m}$ (.0000003 Inches) or better.

3.2.5 Each axis shall be controllable by manual joystick and direct computer control (DCC).

3.2.6 The minimum speed range for the linear ( $x-y-z)$ axes shall be from zero to $20 \mathrm{~mm}$ (.75 Inches) per second.

3.2.7 The minimum acceleration range for the linear ( $x-y-z)$ axes shall be from zero to $500 \mathrm{~mm}(20$ Inches) per second ${ }^{2}$.

3.2.8 The minimum scanning data sampling rate shall be 200 points/second.

3.2.9 Machine isolation. The machine measuring structure shall be suspended on an air isolation system that provides auto leveling and active vibration isolation from the supporting foundation (factory floor). 
3.2.10 An air dryer/conditioner shall be supplied to condition plant compressed air to the necessary requirements for the machine air bearing supply.

\subsection{Measuring System - Tactile system}

3.3.1 The probing system shall use a silicon piezo-kinematic dynamic scanning device, capable of multi-point measurements. The probing system shall also be capable of operating in singlepoint (non-scanning) mode).

3.3.2 The probing system shall employ micro-probe technology with the ability to use probe styli down to $.05 \mathrm{~mm}(.002 ")$

3.3.3 The probe head resolution shall be $.001 \mu \mathrm{m}$ (.04 microinchs) or better.

3.3.4 In single point mode, the probing system shall detect contact and transition from an approach velocity to an electronically controlled null settling state and then acquire the measuring point.

3.3.5 In single-point touch mode, the probing system shall have a minimum data collection rate of 1 point per 2 seconds.

3.3.6 The probing system shall provide vector approach capability.

3.3.7 In scanning mode, the system data collection rate shall be a minimum of 100 points per second.

3.3.8 The scanning speed shall be variable with a minimum range of zero to $20 \mathrm{~mm}(0.78 \mathrm{Inches})$ per second.

3.3.9 The probing force shall be $0.5 \mathrm{mN}$ nominally.

3.3.10 The probing system shall be able to sense in five directions ( $+\mathrm{X},-\mathrm{X},+\mathrm{Y},-\mathrm{Y}$, and $-\mathrm{Z}$ directions.)

3.3.11 The probing system shall be able to automatically select a suitable scanning speed and accuracy based on the required precision of the scan and the configuration of the measurement.

3.3.12 The maximum dimensions of the probe head shall be $10 \mathrm{~mm} \times 10 \mathrm{~mm} \times 10 \mathrm{~mm}$.

3.3.13 The probe head shall be capable of operation with a probe extension length of $7 \mathrm{~mm}(0.28$ inches), measured from the piezo element to the probe ball. This applies to any mounting position through full range of probe head movement in all axes.

3.3.14 Extra probe tactile sensor/piezo element sensors shall be provided with a sphere size of 0.12 $\mathrm{mm}$ and $0.3 \mathrm{~mm}$. The quantity shall be ten (10) each.

3.3.15 A probe calibration sphere shall be supplied with a sphericity not to exceed 0.04 microinch $(0.001 \mu \mathrm{m})$. The calibration sphere shall have a minimum diameter of $6.0 \mathrm{~mm}(0.24 \mathrm{inch})$ and shall be mounted on a suitable base.

3.3.16 A master probe shall be provided with a diameter of $0.3 \mathrm{~mm}$ and a shaft length of $4 \mathrm{~mm}$.

3.3.17 Collision protection shall be provided to prevent probe collisions. The probe shall detect and avoid collisions to an approach velocity of $5 \mathrm{~mm} / \mathrm{s}$. Reasonable collision protection shall also be provided for contact with the $Z$ column and other components such as the probe head. The collision system shall provide adequate protection to guard against a compromise of the machine certified calibration. 
3.3.18 A camera based navigation system shall be provided to provide clear viewing of the tactile micro-probe to aid in positioning the probe. The optical navigation system shall provide highresolution images to a separate video display system. The video display system shall be provided with the system.

\subsection{Measuring system - Optical sensor}

3.4.1 The optical measuring system shall be integrated into the measuring machine such that contact measurements and optical measurements can be acquired on a part in the same setup. The tactile and optical systems shall be fully software integrated so that the part origin and coordinate system are common between both systems.

3.4.2 The optical system shall employ a high resolution video camera system using black and white CCD.

3.4.3 An image processing module shall be provided for complete integration into the image analysis system.

3.4.4 The telecentric lens system shall be provided and shall employ a fixed focal length.

3.4.5 An auto-focus system shall be provided and the focus plan shall be in the same plane as the tactile system. Focus shall be both manual and DCC (Direct computer control)

3.4.6 The lens system shall employ a fixed magnification between 10X and 15X.

3.4.7 The working distance of the lens system shall be between $10 \mathrm{~mm}$ and $20 \mathrm{~mm}$.

3.4.8 The lighting system shall be as follows:

3.4.8.1 A sub-stage telecentric transmitted light shall be provided. The sub-stage transmitted light shall be transmitted from the source into the measuring volume using fiber optics.

3.4.8.2 A reflected quadrant LED ring light shall be provided.

3.4.8.3 All lighting systems shall be usable in any combination and shall be fully programmable for onoff states, brightness and zoned illumination.

\subsection{Temperature Compensation}

3.5.1 The measuring scales in all three mechanical bridge axes shall be fabricated from a low thermal temperature coefficient material such as "Zerodur" or equivalent ( "Zerodur" is a trademark of Schott Glass Technologies, Inc.).

3.5.2 The system shall provide temperature correction for part temperature. The system shall consist of a minimum of two (2) probes and shall have magnetic or other means to attach the temperature sensors to the part.

3.5.3 The temperature system shall be interfaced to the CMM computer system for automatic temperature corrections.

3.5.4 The temperature system shall have a 0.1 degree Celsius ( 0.18 degree Fahrenheit) or smaller resolution and 0.2 degree Celsius ( 0.36 degree Fahrenheit) maximum uncertainty.

\subsection{Control System}

3.6.1 The control system shall provide 4-axis measuring (with optional rotary table) and 3dimensional dynamic scanning capability for the tactile system. 
3.6.2 The control system shall not employ embedded non-removable hard drives. If the control system requires a hard drive, that hard drive must be mounted in a removable carrier and receiving frame to permit the drive to be easily removed and stored away from the machine. Three (3) hard drives and three (3) carriers must be provided if the removable drive system is employed.

3.6.3 All linear ( $x-y-z)$ motions of the machine shall be provided with power feed over their full range of feed rates and measuring ranges.

3.6.4 CNC control shall provide simultaneous control and movement for the three linear ( $\mathrm{x}-\mathrm{y}-\mathrm{z})$ axes to automatically measure parts, make vector (diagonal) moves, and to dynamically collect 3dimensional scanned data.

3.6.5 The control system shall operate both automatically from commands supplied by a CNC part (work piece) inspection program and manually from commands entered by keyboard and remote control box.

3.6.6 The control system shall operate without damage in an ambient temperature range of 59-86 degrees F. and a relative humidity range of $40-80 \% \mathrm{RH}$.

3.6.7 A portable control shall be provided to enable the operator to control machine functions while in a close observation position. This control shall provide the following minimum capabilities: losing position and restart without returning to the beginning of the automatic cycle (pause).
a. Interruption of CNC inspection and motion halt. Shall be able to stop all motion without
b. Emergency stop of $\mathrm{X}, \mathrm{Y}$ and $\mathrm{Z}$ axes drive motors without interrupting power to the computer control system or loss of inspection data (emergency stop).
c. Manual joystick control for each linear axis of machine motion and rotary axis. Joystick shall provide variable speed control which will provide rapid travel and precision step in machine and work-piece coordinates.
d. Indexing/positioning of the probe head styli position.

3.6.8 The Numerical Control System shall include, as a minimum, the following features:

a. Minimum linear unit input, $0.00005 \mathrm{~mm}$. and 0.000002 in.

b. Floating zero reference.

c. Measuring scale feedback.

d. Absolute and incremental programming.

e. Programmable and manual (from computer) Millimeter or Inch selection.

f. Programmable and manual automatic probe radius compensation.

g. American Standard Code for Information Interchange (ASCII) data.

h. Automatic acceleration and deceleration.

i. Programmable resolution of output data with maximum resolution of $.0005 \mathrm{~mm}(.000020$ in.)

3.6.9 The CMM controller shall incorporate features that incorporate metrology interoperability by using control commands that comply with the International Association of CMM Manufacturers I ++ DME specification. Reference the National Institute of Standards and Technology (NIST), I ++ DME Test Suite Version 3.0 to test compliance with metrology interoperability.

\subsection{Computer Hardware Requirements}

3.7.1 All computer hardware shall be a current and supported model by that Manufacturer. The system computer hardware must be capable of operating the latest version of the operating system and latest version of the measuring software for a minimum of one (1) year from the 
date of machine acceptance or fifteen (18) months from the date of machine delivery, whichever comes first. If, during this described period, the hardware requires update or replacement, those upgrades or replacements shall be provided and installed on the machine at no cost to the Buyer.

3.7.2 The computer shall be an IBM compatible personal computer or workstation and shall be loaded with the latest version and service pack release of Microsoft Windows XP.

3.7.3 The minimum computer processor for the system shall be a Pentium IV with a minimum clock speed of $3.4 \mathrm{GHz}$, a minimum of $2 \mathrm{~Gb}$ MB of RAM and hard drives with a minimum capacity of $200 \mathrm{~GB}$.

3.7.4 The system shall include a flat panel high resolution computer monitor with a minimum size of 20 " and a minimum resolution of $1920 \times 1200$. The monitor shall comply with MRP-II guidelines for low frequency electric field, magnetic field, and static electricity emissions.

3.7.5 The computer system shall include an optical mouse, alpha-numeric keyboard, 3.5" floppy diskette drive, printer and all peripheral interface cables.

3.7.6 A color Laser printer shall be supplied with 600dpi minimum resolution.

3.7.7 The computer system drive shall employ a removable hard drive system to facilitate changing of hard drives without opening the computer enclosure. A hard drive tray carrier and receiving frame must be employed to permit the disk drive to be removed and stored away from the machine. A remote drive silo may be employed in lieu of mounting the receiving frame in the computer chassis. Heavy duty ruggedized carriers and receiving frames must be employed. Carriers with retaining screws are preferred.

3.7.8 The computer system shall be supplied with three (3) hard drives and three (3) hard drive carrier frames.

3.7.9 A uninterruptible power supply or other suitable line conditioning shall be supplied.

3.7.10 User's manuals for all installed software must be provided.

3.7.11 All original software must be provided on CD or other original media.

\subsection{Software Requirements}

3.8.1 All software shall be the latest released version. If, during a one (1) year period from the date of machine acceptance, a later version is released, those upgrades shall be provided and installed on the machine at no cost to the Buyer. User's manuals for all installed software must be provided.

3.8.2 The software shall have a "learn" programming capability that shall allow full automatic inspection of parts. The software shall have the ability to perform best-fit data analysis on lines, planes, circles, spheres, conic sections, cones, cylinders, solid ellipse, and ellipsoids. The software shall provide part geometry evaluations to the ASME Y14.5M-1994 specification. Software shall provide best-fit and curve fitting capability for scanned data. The software shall have report generation capability. The software shall include a DMIS translator or postprocessor. Specific requirements of the software are outlined below:

3.8.3 The measurement software for generation of CNC programs shall be CAD model based with an integrated CAD kernel. 
3.8.4 The measurement software system shall be able to import models from Pro/Engineer and SolidWorks and shall be able to extract GD\&T information from the solid model per AP203. If a separate module is required to extract tolerance information from the module, that module shall be provided.

3.8.5 The measuring software system shall be capable of generating an inspection plan using the available solid-model geometry, solid-model tolerance information, probe setups, and fixturing. The system shall be capable of simulating and inspection plan to evaluate the measuring routine and to prevent probe crashes. The software system shall have the capability to generate an inspection plan which incorporates both tactile and optical measuring features.

3.8.6 The measurement software shall have the ability to perform off-line programming (planner) with the ability to simulate probes and fixture setups.

3.8.7 The measurement and control software must provide Manual or Direct Computer Control (DCC) of the CMM in tactile and optical modes.

3.8.8 The measurement and control software must employ automatic software or firmware correction to compensate for systematic errors of displacement, rotation and squareness. The Buyer shall be provided unlimited access to and explanation of any data files with error correction information.

3.8.9 The measurement and control software shall provide for electronic adjustment of probe head, servo system tuning, and other controller tuning parameters. The Buyer shall be provided the test software and access to these adjustments and parameters.

3.8.10 The Buyer shall be provided with all software and hardware required for unlimited creation, modification, and storage of automatic error correction data, for squareness and linear displacement (linearity) adjustments.

3.8.11 The measurement and control software must provide automatic correction of part feature size and location using actual probe stylus diameter and angle of contact with the part.

3.8.12 The measurement and control software must provide automatic correction of all measurements for thermal expansion and contraction the part being measured. The software shall allow both manual and automatic CNC input of the part materials thermal coefficient of expansion and the temperature of the part and measuring scales.

3.8.13 The measurement and control software must provide calibration (qualification) of probe configurations at various spatial orientation attitudes, and must store a minimum of one hundred (100) probe calibrations.

3.8.14 The measurement and control software must provide automatic transfer of probe configurations between the probe change rack and probe head by manual or CNC part inspection program command.

3.8.15 The measurement and control software must provide detection of missing part features or broken probes when an unexpected probing occurs or no probing occurs within a predetermined range. If the above detection occurs, a fault condition shall be initiated.

3.8.16 The measurement and control software must provide for creation and editing of DCC inspection routines in an On-line and/or Off-line mode. 
3.8.17 The measurement and control software must provide a teaching mode on the CMM. In this mode the operator manually drives machine to the datum(s) and enters the type of datum; manually drives to other locations and enters feature type, tolerance, and nominal location; and then saves the routine for automatic measurement of subsequent parts. Subsequent parts may be oriented within 3 degrees in any plane and at a different reference point within the work volume.

3.8.18 The measurement software shall be capable of generating geometric features such as circles, ellipses, lines, planes, cylinders, cones, spheres, free-form contours from measured points. Least squares techniques as well as circumscribed and inscribed constructions shall be provided.

3.8.19 The measurement software shall be capable of automatic part alignment to datum's using any valid combination of geometrical features such as: plane, circle, line, arc, diameters, point, midpoint, centerline, cylinder, slot, sphere, and angle.

3.8.20 The measurement software shall be capable of translating and rotating measured part coordinate systems. Tactile and optical systems shall be capable of reporting in the same coordinate system.

3.8.21 The measurement software shall be capable of geometrical constructions from actual measured part features, as listed below:

a. Intersection point of two lines.

b. Intersection of two circular arcs.

c. Intersection of a line and a circular arc.

d. Intersection of a line and a plane.

e. Intersection of two planes.

f. Construction of plane \& computed flatness

3.8.22 The measurement software shall be capable of the following:

a. Conversion of rectangular coordinates to polar coordinates.

b. Conversion of polar coordinates to rectangular coordinates.

c. Conversion from inches to $\mathrm{mm}$ and from $\mathrm{mm}$ to inches.

d. Ability to use multiple mathematical operations on measured results (add, subtract, multiply, divide and trigonometric functions).

e. Multiple coordinate systems.

f. Conditional statements in program

3.8.23 Inspection routines shall be provided to determine the size, location and orientation of geometrical features such as: line, plane, hole, boss, cylinder, cone, sphere, slot, rib, and secondary datum's. All routines shall be capable of entering data for a minimum of 1000 probing points and reporting maximum value, minimum value, and range, as well as nominal or least squares values.

3.8.24 Evidence shall be provided that the software algorithms were tested using standard data sets from NIST or PTB. Data shall be provided to show the difference between the calculated result and the accepted result of the data sets used for testing.

3.8.25 Inspection routines per ASME Y14.5M-1994, "Dimensioning and Tolerancing," shall be provided as follows: 
a. True Position Regardless of Feature Size (RFS)

b. True Position Maximum Material Condition (MMC). (Note 1 below.)

c. Limit

d. Inside and Outside Profile

e. Bilateral and unilateral tolerances

f. Projected tolerance zones

g. Form

h. Parallelism

i. Perpendicularity

j. Angularity

Note 1: The minimum ASME Y14.5 feature MMC \& LMC compliance shall be on a "feature by feature" basis, independent from other features referenced to the same Datum's.

Note 2: All routines shall be capable of entering data for a minimum of 100 probing points and outputting maximum value, minimum value, and range, as well as nominal or least squares values.

3.8.26 An image analysis module shall be provided for the optical system to perform the same constructions, alignments and geometric features as stated above for the tactile system (2-D applications only).

3.8.27 The image analysis module for the optical system shall provide the following capabilities:

a. Automatic edge detection

b. Analysis of gray scale images

c. Autofocus capabilities

d. Edge build-up and automatic correlation algorithms

e. Optical scanning capability to automatically and continuously scan an unknown curve. Capability must be provided to enter the start point, end point, scan direction, scan speed, and filter parameters. Scanning must adapt to open or closed contours.

3.8.28 The image analysis software for the optical system shall provide "best-fit" analysis of scanned contour data. Software shall have the ability to compare the scanned curve to imported "IGES" or "DXF" CAD masters.

3.8.29 A specialized package for statistical analysis of inspection results shall be provided.

3.8.30 Output routines for displaying the nominal program information and inspection data shall be provided as follows:

a. Output to the printer consisting of the measurement point identification or sequence number, nominal dimension, actual (measured) dimension, maximum and minimum tolerance limits, deviation from nominal and amount out-of-tolerance.

b. Graphic output to the CRT and printer of the "best-fit" analysis of scanned data against CAD masters. Color deviation plots from nominal are required.

c. The ability to graphically display inspection results on the CRT and printer.

d. Display operator instructions on the CRT which are included in the CNC part inspection program.

e. Store all output data on magnetic media

3.8.31 In addition to the above output routines, a routine or means shall be provided to write single or multiple measured results to a user specified data file. This capability shall allow the user to choose any measured result in a CNC run and write that result to a standard ASCII data file or 
Excel spreadsheet. This routine will also write headers or user specified identifiers such as point number, etc to the data file.

3.8.32 A DMIS (Dimensional Measuring Interface Standard) translator shall be provided.

\subsection{Performance Requirements}

3.9.1 All accuracy and repeatability performance requirements are stated in millimeters. The requirements shown in parentheses shall also apply in U.S. Customary inch (in) units.

3.9.2 The latest issues of the following standards apply to this equipment. Requirements of this specification take precedence in the event of conflicts:

Standard VDI 2617-6

International Standards ISO 10360-2 and ISO 10360-4

3.9.3 Uncertainty requirements apply with the machine located in a $20.0^{\circ} \mathrm{C}+/-0.50^{\circ} \mathrm{C}\left(68.0^{\circ}+/\right.$ $0.9^{\circ} \mathrm{F}$ ) environment with a maximum spatial gradient (horizontal and vertical) of $+/-0.10^{\circ} \mathrm{C} /$ Meter and maximum temperature/time gradient of $+/-0.20^{\circ} \mathrm{C} /$ hour $\left(+/-.36^{\circ} \mathrm{F} /\right.$ hour $)$ and $+/-$ $0.40^{\circ} \mathrm{C} /$ day $\left(+/-0.72^{\circ} \mathrm{F} /\right.$ day). Humidity will be a minimum of $30 \% \mathrm{RH}$ and maximum of $50 \%$ $\mathrm{RH}$. The ambient vibration will be less than $0.005 \mathrm{~g}$ below $10 \mathrm{~Hz}$.

3.9.4 Axial Straightness. Each axis shall be tested for straightness by using a straight edge provided by the Buyer. Three runs shall be made with measuring intervals of $5.0 \mathrm{~mm}(.2 \mathrm{inch})$ along the straight edge. Straightness for all runs shall not exceed $0.2 \mu \mathrm{m}$ (8 microinchs) for any axis. Additional uncertainty shall be allowed in this specification to accommodate the actual uncertainty of the Buyer's artifact. This applies with the computer error correction activated.

3.9.5 Planar Squareness. Each of the machine planes shall be tested for squareness using a square provided by the Buyer. Three sets of runs shall be made for each axis. The two faces of the square shall be measured at $5.0 \mathrm{~mm}$ ( 0.2 inch intervals) along a line and a best-fit line shall be established for each face. The squareness shall be determined and shall be no greater than 0.4 arc second for all three runs in each plane. Additional uncertainty shall be allowed in this specification to accommodate the actual uncertainty of the Buyer's artifact. This applies with the computer error correction activated.

3.9.6 The computer error correction for straightness of any axis shall not exceed 60 microinches $(1.50 \mu \mathrm{m})$.

3.9.7 The computer error correction for rotations of any axis including squareness shall not exceed two (2) arc seconds.

3.9.8 Volumetric Length Measuring Error - Tactile Probe. The Volumetric Length Measuring Uncertainty shall not exceed the following:

$$
\begin{aligned}
& \mathrm{MPE}_{\mathrm{E}}=+l-(0.25 \mu \mathrm{m}+\mathrm{L} / 600) \mu \mathrm{m} \text { (where } \mathrm{L} \text { is measuring length in } \mathrm{mm} \text {.) } \\
& \mathrm{MPE}_{\mathrm{E}}=+l-(10 \mu \mathrm{in} .+1.66 \mathrm{ppm}) \quad \text { (parts per million of measuring length) }
\end{aligned}
$$

This applies throughout the entire measuring volume. Volumetric length measurements shall be done in accordance with ISO 10360-2. 
3.9.9 Probing Error - Tactile probe. The discrete or single point probing error for a simple, single probe configuration shall not exceed the following:

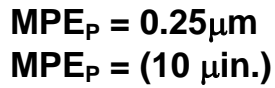

Probing error measurements shall be done in accordance with ISO 10360-2.

3.9.10 Scanning Probing Error - Tactile probe. The probe head scanning error shall not exceed the following:

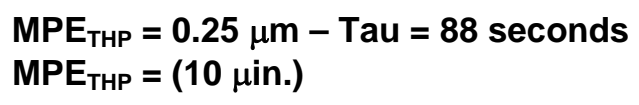

Probing error measurements shall be done in accordance with ISO 10360-4

3.9.11 Uncertainty - Optical System. The 2-D optical system shall not exceed the following:

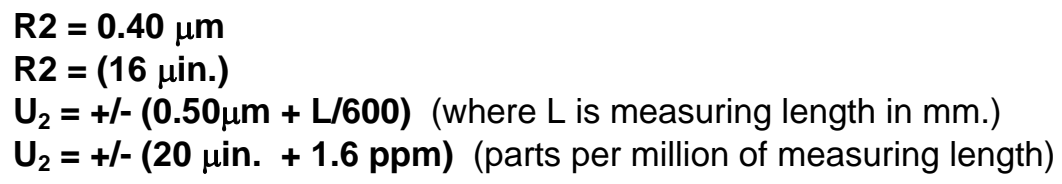

Optical uncertainty shall be done in accordance with VDI 2617-6

\subsection{OTHER CONTRACTUAL REQUIREMENTS}

\subsection{Training}

4.1.1 The Seller shall provide, at a minimum, training courses at the Buyer's facility for each of the following subjects:

a. Basic machine operation and piece part programming.

b. Advanced operation and piece part programming.

c. Basic Maintenance (electrical/electronic) for the machine.

d. Basic Maintenance (mechanical) for the machine.

e.Basic preventative maintenance for electrical and mechanical systems.

4.1.2 For training conducted at the Seller's facility one set of all materials such as manuals, machine drawings and documents used in the instructional courses shall be furnished by the Seller to each student. Manuals provided for the training courses shall be in addition to the quantity defined in Section 4.3, Drawings and Manuals.

4.1.3 After installation of the machine and acceptance tests at the Buyer's facility are complete, the Seller shall provide operator training for a minimum of two (2) operators/programmers for topics listed in 4.1.1.a and b

\subsection{Inspection And Acceptance}

4.2.1 The Seller shall be responsible for the performance of all inspection requirements as specified herein. The Seller shall provide procedures, equipment, and material required for testing. Any test facilities used, other than the Seller's factory, must have prior approval of the Buyer. The 
Buyer may elect to witness the Seller's inspection of the equipment and shall be notified a minimum of two (2) weeks prior to the anticipated testing date. If the machine is inspected in any location other than the U.S.A, the Seller shall notify the Buyer a minimum of three (3) months prior to the anticipated testing date. In addition, the Buyer may elect to witness proof of compliance with the Performance Requirements of this specification at the Seller's site prior to shipment to the Buyer. In this case, the same notification requirements apply.

4.2.2 The machine and the control unit shall be subjected to the following tests:

4.2.2.1 The machine shall be operated in accordance with the Seller's standard operating test procedure to check machine response to commands introduced in each of the modes of operation. Tests made in the manual and automatic modes shall include checks of over-travel limit switches, safety stops between moving components and response to manual and automatic inputs. Tests made in the automatic mode shall include use of program(s) which are to be supplied with the machine.

4.2.2.2 All test requirements shall be duplicated after installation of the machine in the Buyer's facility.

4.2.3 Final acceptance of the machine shall take place after installation in the Buyer's facility and when the Buyer determines that the machine meets the specification.

\subsection{Drawings And Manuals}

4.3.1 Drawings and Manuals shall be delivered to the Buyer with the machine. All drawings and manuals shall be original copies for the subject equipment and shall be written in American English. Drawings and manuals shall be provided on CD-ROM media compatible with Microsoft Windows ${ }^{\circledR}$-based PC applications.

4.3.2 A minimum of sixty (60) days prior to shipment of equipment, the Seller shall furnish four (4) original copies of the following information, which may be included in one manual.

4.3.2.1 Installation Information - This information shall contain drawings showing location and sizes of all required electrical, air, water, drain, and other utility services, including consumption (flow rates), minimum and maximum inlet pressures, the maximum pressure drop through the equipment, and interconnections between ancillary equipment. It shall also contain recommended installation procedures, including weights of individual components and locations of lifting points.

4.3.2.2 Floor Plans - Scaled plan view, front elevation and end elevation with dimensions, and workspace clearance dimensions.

4.3.2.3 Operator's Manual(s) - These manuals shall contain a description of the system configuration, operator's maintenance and general care, and a list and description of operation of all system controls and indicators. Complete information shall be contained in the operation manual to provide the operator with turn-on, operation, and turn-off procedures.

4.3.2.4 Programming Manual(s) - These manuals shall contain complete programming information and documentation, including tape formats for all word addresses in inch and metric.

4.3.2.5 Maintenance Information - This information shall include machine drawings (mechanical systems, electrical schematics, pneumatic/hydraulic drawings, etc.), spare parts list, and basic machine logic information.

4.3.2.6 Material Safety Data Information - The Seller shall provide an OSHA compliant Material Safety Data Sheet (MSDS) for each chemical (material) provided with the equipment or for each chemical that is recommended by the manufacturer for warranty protection. This includes, but 
is not limited to, oils, greases, refrigerants, adhesives, and solvents as examples. The MSDS shall be the most recent copy or revision from the chemical (material) manufacturer.

\subsection{Shipping Requirements}

4.4.1 Before shipping the equipment the Seller shall remove all components warranting special consideration, and package them in separate containers suitable for shipping fragile parts.

\subsection{Installation}

4.5.1 The Seller shall specify to the Buyer detailed instructions with respect to any site requirements that must be performed by the Buyer prior to arrival of the factory Engineer.

4.5.2 The Seller shall uncrate and assemble the machine at the installation site. Preparation of the installation site will be the responsibility of the Buyer.

4.5.3 The Seller shall perform all further installation, including initial start-up of the machine.

\subsection{Service Requirements}

4.6.1 The services of a qualified factory trained Engineer to complete installation and start-up of the equipment, including all the necessary special fixtures and test artifacts required for the acceptance tests, shall be provided by the Seller. The factory trained Engineer shall be a citizen of the United States. Note: The Seller's representative shall be made aware that the Kansas City plant is a smoke-free workplace, that safety glasses with side shields are required, and that safety shoes are recommended and may be required in certain areas.

\subsection{Options}

4.7.1 A listing, including price, shall be furnished of all available machine accessories applicable to the machine being offered.

4.7.2 A listing of available Maintenance Service Contracts for preventive and/or breakdown service for machine/control shall be provided (if offered by the Seller).

4.7.3 A listing of Calibration Services shall be provided (if offered by the Seller).

\subsection{Proposals}

4.8.1 All proposals shall address each and every specification paragraph individually as to compliance/noncompliance. All proposals in which the offered equipment deviates from the specification as stated shall have a written explanation for each paragraph as to why/how the machine does not meet or why/how it exceeds the requirements.

4.8.2 The proposal will be judged technically non-responsive if the requirements of paragraph 4.8.1 are not fulfilled.

4.8.3 It is permissible to propose a factory demonstration machine in lieu of a new machine. Any demonstrator machine shall be cosmetically new in all respects, shall have been in constant possession of the manufacturer, shall meet all the requirements of this specification and shall be offered with the full factory warranty of a new machine. If this option is proposed, the Seller shall supply a complete history of the machine including the original manufacturing date, the total hours of operation and any other known deficiencies. The Buyer reserves the right to examine any proposed demonstrator machine at the Seller's facility prior to the award of any order. 
APPENDIX C

Evaluation of Ultra-High-Accuracy CMM 


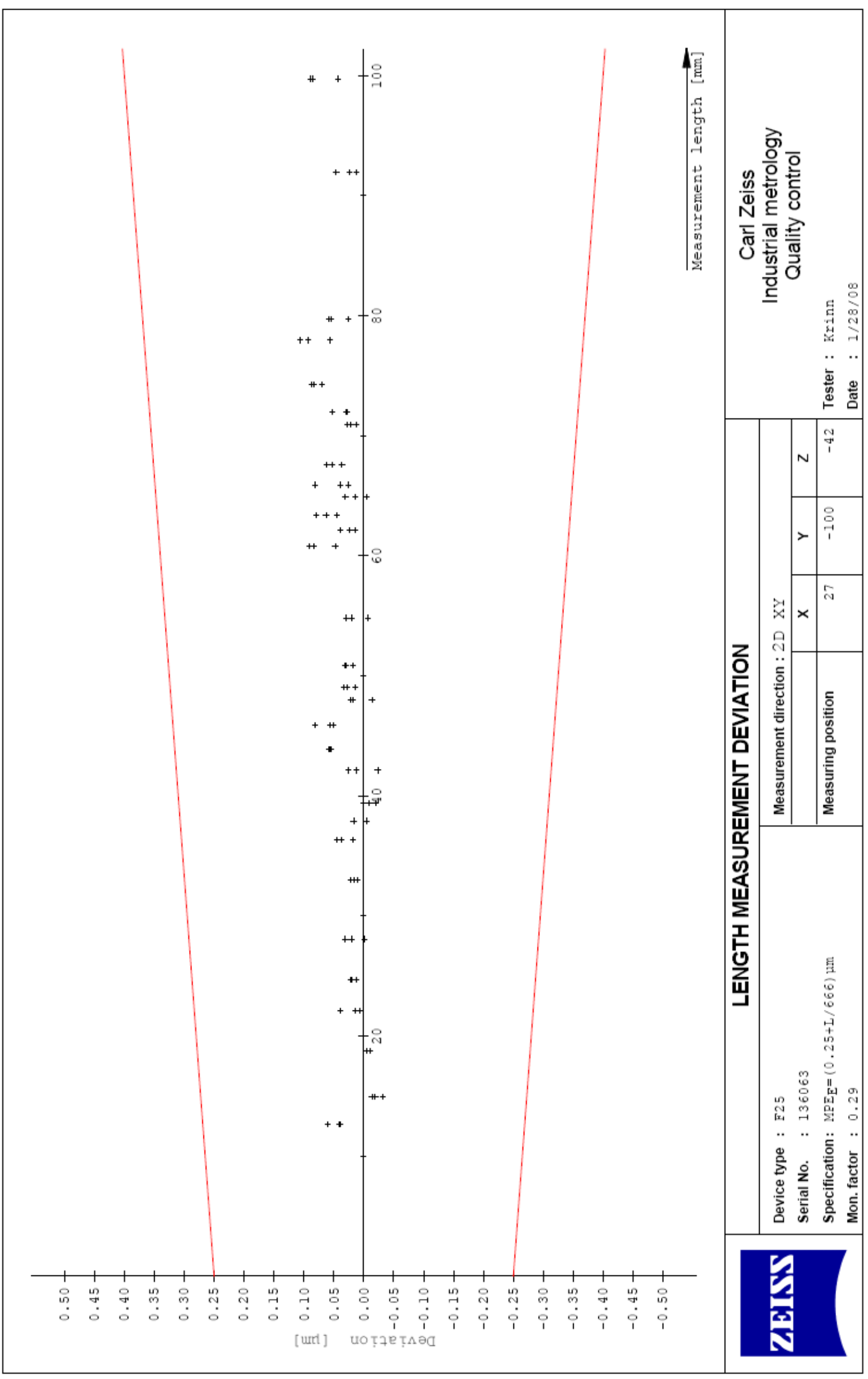




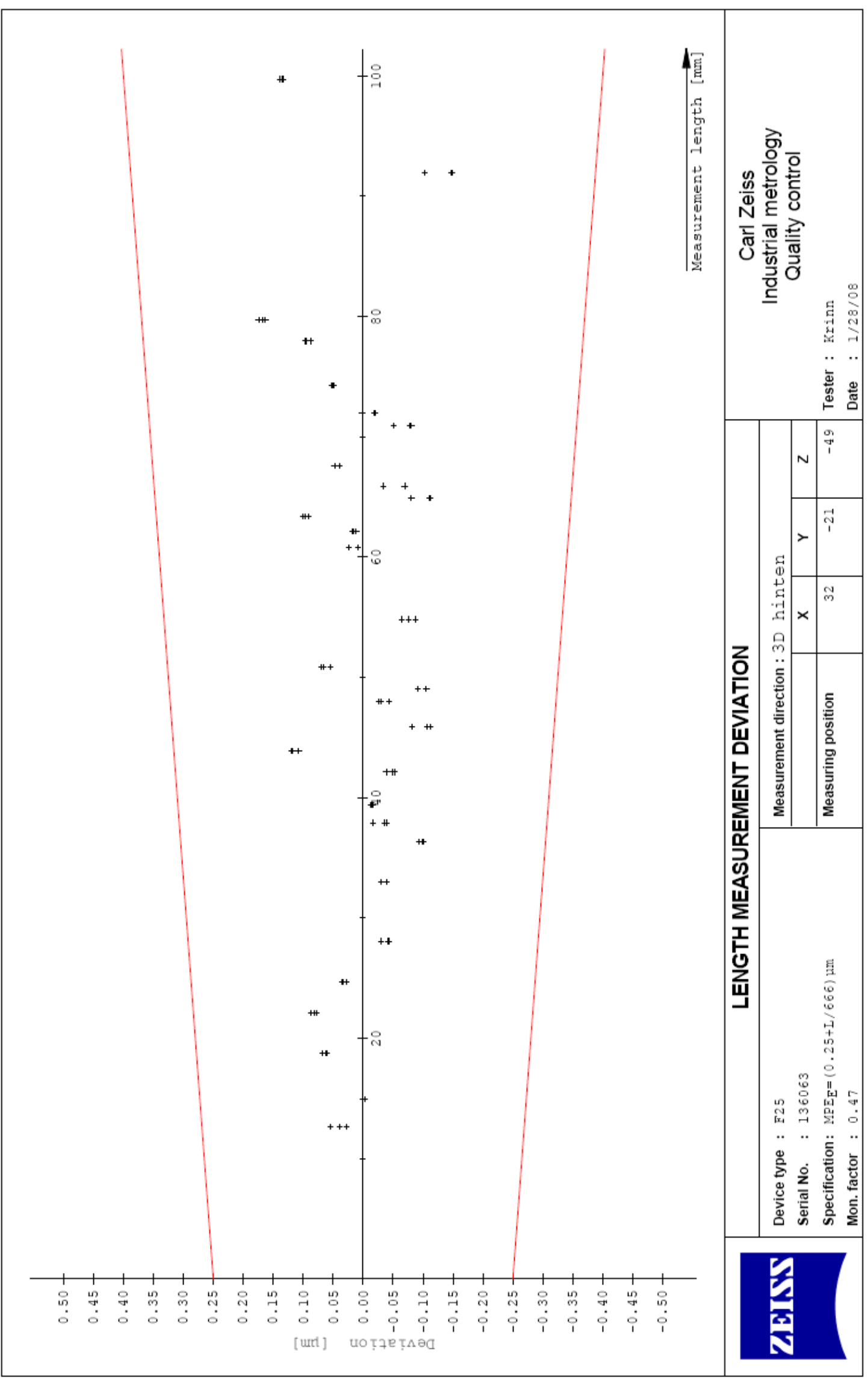




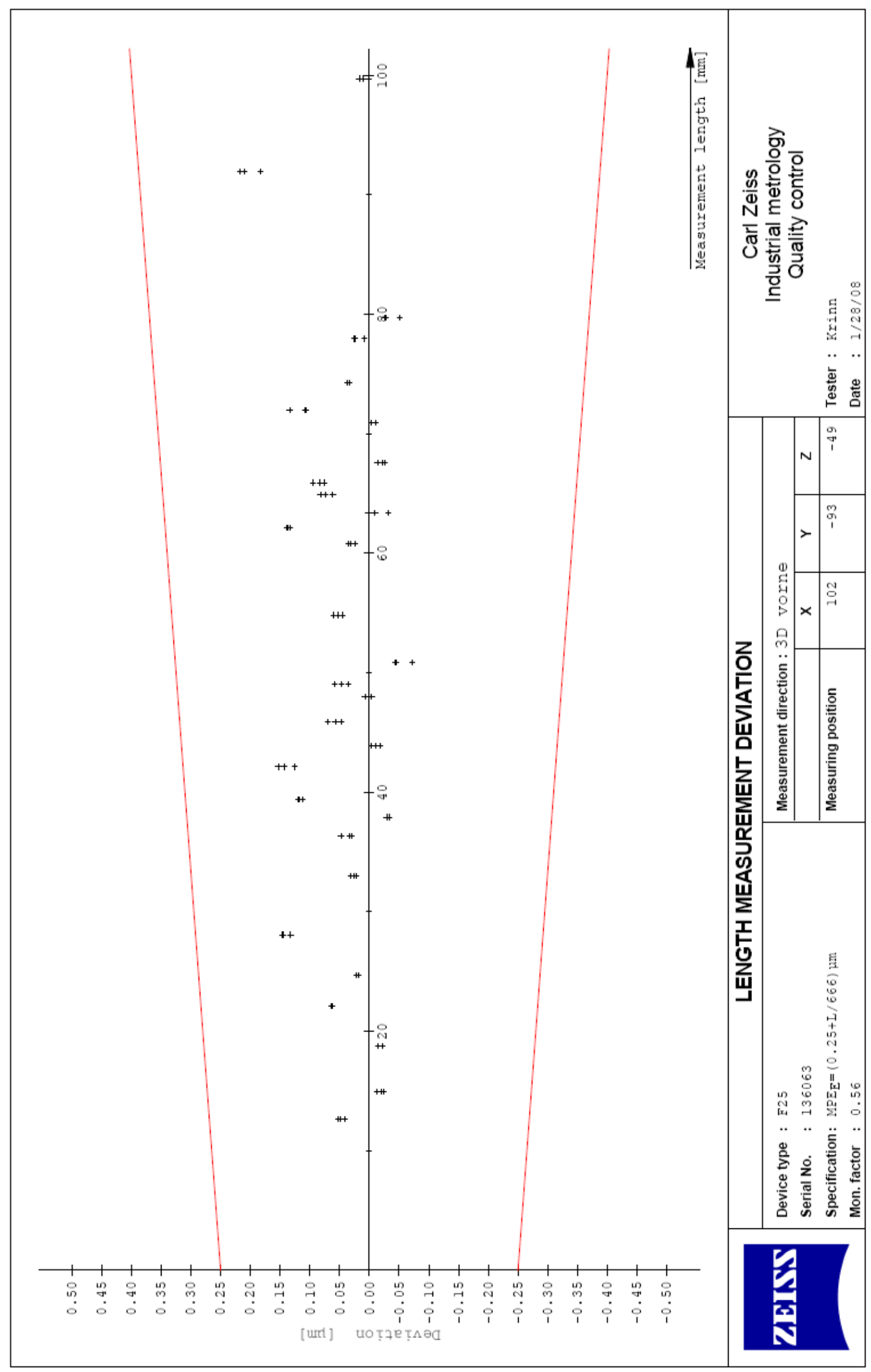

